\title{
A organização do desembarque e o comércio de pescado na década de 1990 em Manaus, Amazonas.
}

\author{
Valdenei de Melo PARENTE ${ }^{1}$; Vandick da Silva BATISTA ${ }^{2}$
}

\begin{abstract}
RESUMO
A maior parte da produção pesqueira do Estado do Amazonas é desembarcada em Manaus, entretanto, as características de organização do apoio à produção e da comercialização neste centro, pouco têm sido avaliadas ou consideradas nas discussões para o desenvolvimento do setor. O presente trabalho visa apresentar estas características de forma a estabelecer um referencial histórico sobre a organização do desembarque pesqueiro em Manaus e para subsidiar o planejamento do setor. Entrevistas foram efetuadas com diversos atores deste setor, de forma a cobrir o mosaico de alternativas que existem para o abastecimento de pescado. Há quatro tipos de agentes de comercialização atacadista de pescado para Manaus: o barco de pesca, o despachante, $o$ atravessador e os frigoríficos. O despachante aparece como ator central no processo produtivo pesqueiro no período, seja por financiar as viagens e operações de comercialização, ou por executar a ligação entre os produtores-pescadores e os comerciantes de pescado. Exceção a esta regra ocorre com o "pescador ribeirinho autônomo", o qual pesca com seus próprios meios e comercializa sua produção com compradores sem intermediação. No comércio varejista, os feirantes são os mais importantes, sendo a Feira da Panair responsável por cerca de $20 \%$ do abastecimento do pescado in natura em Manaus. Os supermercados e os pequenos comerciantes são os demais agentes varejistas, cuja participação na comercialização da produção era ainda pequena, porém financeiramente é maior visto que disponibilizam produtos com valor agregado e portanto preços maiores a mercados de classe média que o dos feirantes.
\end{abstract}

\section{PALAVRAS-CHAVE}

Pesca artesanal, comercialização, produtos pesqueiros, microeconomia, Manaus.

\section{Landing and fish commercialization in the decade of 1990 in the Manaus fishing harbor, Amazonas, Brazil.}

\begin{abstract}
Manaus is the main commercial center for fish prodution in the state of Amazonas. However, its characteristics of commercialization have not been evaluated in order to assist the development of the fishery sector. The present paper presents these characteristics to establish a historical referential about this organization and to subsidize governmental planning. Interviews were performed with several players, in order to cover the alternatives that exists for fish provisioning. There are four types of agents of fish wholesalers in Manaus: the fishing boat, the middleman-auctioneer, the middleman-seller and the freezing bouse. The middleman-auctioneer is a central agent. He finances the fishing trips and the commercialization operations or act as the middleman between the producer-fishermen and fish merchants. Exception to this rule is the autonomous riverine fishers, who uses personal resources, including boat and gear. This fisher sells prodution to consumers without intermediaries. In the retail trade, the street market salesman is the most important, considering that the Panair Fish Market in Manaus is responsible for providing about $20 \%$ of the fish in natura in Manaus. Supermarkets and small merchants are other retail agents. Although their participation in commercialization of the prodution is small, financially it is not small due to the fact that they sell to middle class markets fish with joint value with higher prices than those of the street market salesman.
\end{abstract}

\section{KEYWORDS}

Artisanal fishery, commercialization, fish products, micro economy, Manaus.

\footnotetext{
${ }^{1}$ Universidade Federal do Amazonas, Faculdade de Estudos Sociais, Departamento de Economia e Análise, Campus Universitário, Manaus, AM, 69077-000, e-mail: parentes@argo.com.br

${ }^{2}$ Universidade Federal do Amazonas, Faculdade de Ciências Agrárias, Departamento de Ciências Pesqueiras, Campus Universitário, Manaus, AM, 69077-000, e-mail: vbatista@ufam.edu.br
} 


\section{INTRODUÇÃO}

A pesca apresenta uma complexidade em sua estrutura de organização de comercialização da produção (Zamosc, 1979; Loureiro, 1985; Mello, 1993). Os elementos chave desta complexidade são a alta perecibilidade do produto, a imprevisibilidade e o alto risco associado, formando fatores que usualmente limitam a atuação de investidores (Junk \& Honda; 1976; MacKenzie, 1983; Mendes, 1989).

Problemas, como a descapitalização da maioria dos produtores, as precárias condições de acondicionamento nos barcos e a inexistência de infra-estrutura portuária e de frios, são condições que se destacam dentre as manifestações do fraco desenvolvimento das forças produtivas na pesca (e.g. Mello, 1993), constituindo fatores propícios à dominação do capital comercial.

No caso de atividades pesqueiras, encontramos o capital comercial como parte integrante do processo de acumulação e como forma localizada de manifestação do capital, principalmente em se tratando de ramos onde predominam relações não-capitalistas de produção. Neste sistema, todas as relações de trabalho existentes são utilizadas "como recurso para garantir a sua própria expansão (do sistema capitalista), como forma de garantir a produção não-capitalista do capital naqueles lugares e setores da economia que se vinculam no mundo capitalista da produção através das relações comerciais" (Martins, 1998). Também deve ser avaliado se as formas de organização da produção e de circulação de mercadorias numa determinada sociedade expressam os interesses dominantes procurando subordinar as atividades geradoras de riqueza (Maluf, 1992), o que tem implicações para a eficiência da atividade produtiva e para a distribuição do capital gerado.

Assim, as condições de organização da produção tendem a ser refletidas na organização da comercialização (McGoodwin, 2002), onde usualmente predomina uma variada e complexa intermediação comercial, o que determina um sistema no qual cada agente procura se apropriar da maior parcela possível do excedente gerado na produção.

No presente trabalho, discutiremos a estrutura de organização da comercialização do pescado em Manaus, mostrando como ocorre o processo de comercialização, bem como destacando as figuras centrais da cadeia de intermediação entre o pescador e o consumidor final. O objetivo central é entender o papel dos agentes do setor na estrutura de mercado da região, subsidiando a compreensão da dinâmica operacional do setor comercial pesqueiro e sua importância para o manejo da atividade.

\section{MATERIAL E MÉTODOS}

Em 1990 foram efetuadas entrevistas informais com agentes do setor pesqueiro, sendo posteriormente selecionados e entrevistados representantes dos segmentos atuantes no processo com maior conhecimento do funcionamento do setor. Assim, foram entrevistados três armadores (o armador é o agente social proprietário dos meios de produção e que organiza todo o processo de produção), três despachantes (despachante é o agente responsável pela comercialização do pescado no atacado), dez pescadores, feirantes de cinco feiras municipais de Manaus, funcionários de duas fábricas de gelo e de dois frigoríficos para examinar as relações de trabalho que existem entre eles e a existência de verticalização na atividade. Em 1995 foram entrevistados funcionários de outros quatro frigoríficos, objetivando identificar a sua importância no processo de comercialização. As informações obtidas referemse a:

1. Pescador: experiência na pesca, jornada de trabalho, relações com o armador ou despachante e destino da produção;

2. Armador e despachante: experiência na pesca, propriedade dos meios de produção, participação nas viagens de pesca, participação no processo de comercialização e destino da produção comercializada.

3. Frigoríficos e fábricas de gelo:

3.1. Frigoríficos: capacidade instalada e ocupada, venda de serviços e modalidade de pagamento, destino da produção e participação direta na atividade pesqueira como armador ou despachante ou como proprietário de outras estruturas ligadas à pesca como fábrica de gelo, posto de venda e meios de transporte. Em 1995, coletamos informações referentes à capacidade de estocagem e ocupação, quantidade e espécies adquiridas por mês, quantidade e destino da venda do pescado, participação em outras atividades ligadas à pesca, despesa mensal com o acondicionamento, adiantamentos e custos fixos.

3.2. Fábrica de gelo: participação da pesca no total da venda de gelo, participação direta na atividade pesqueira como armador ou despachante e propriedade de outras estruturas ligadas à pesca como frigoríficos, postos de venda e meios de transporte;

4. Feirantes: Em 1995 foram entrevistados 51 feirantes que atuam em cinco feiras e mercados municipais com o objetivo de coletar informações sobre a venda no varejo realizada por estes agentes. As informações coletadas foram: custos de comercialização, quantidade e espécies comercializadas, fornecedores de pescado, modalidade de pagamento da compra do pescado e condições de trabalho;

4.1. Estimativa da quantidade de pescado comercializada por feirantes das feiras e mercados Manaus Moderna, Panair, Adolpho Lisboa e Cachoeirinha: Para isto tomamos como base os dados fornecidos pelos próprios feirantes que fizeram uma estimativa da quantidade média comercializada por cada um, por semana, na safra e na entressafra. Estas informações foram organizadas segundo o número de feirantes pesquisados, por grupo de quantidades de pescado comercializadas por semana, na safra e na entressafra. Com base na participação relativa do número de feirantes pesquisados em cada intervalo, calculamos para o total de feirantes existentes em cada um dos locais acima mencionados, o número total de feirantes dentro de cada intervalo. Multiplicamos tal valor pelo limite superior do 


\section{ACTA AMAZONICA}

intervalo, encontrando a quantidade total comercializada, por semana, na safra e na entressafra em cada feira e mercado. De posse dessas informações, calculamos o total comercializado na safra, multiplicando a quantidade comercializada por semana por 4,5 semanas vezes 5 meses (agosto-dezembro) e, na entressafra o mesmo raciocínio só que por 4 semanas vezes 7 meses (janeiro-julho);

4.2. Para as demais feiras e mercados, num total de 18 , por situarem-se em bairros mais distantes do centro da cidade à semelhança do mercado Armando Mendes, utilizamos como base a quantidade média comercializada, por semana, na safra e na entressafra pelos feirantes deste último, que foi um dos locais por nós pesquisado. Com essa informação, calculamos para cada feira ou mercado o total comercializado, multiplicando o número total de feirantes existentes em cada, pela quantidade média comercializada por semana, vezes 4,5 semanas, vezes 5 meses para a época da safra, e por 4 semanas vezes 7 meses para o período da entressafra.

\section{RESULTADOS}

\section{Processo de comercialização}

A trajetória da comercialização entre o produtor e o consumidor final de pescado em Manaus apresentou uma cadeia de intermediação formada por comerciantes variados, entre atacadistas e varejistas. A disparidade entre o preço pago ao produtor e o preço pago pelo consumidor atingiu até $910 \%$ durante a coleta de preços efetuada em agosto e setembro de 1995 (Tabela 1).

A forma de como se dá o processo de comercialização é melhor explicitada através da análise discriminada dos agentes e processos de comercialização no atacado e varejo, o que é visto a seguir.

\section{Venda do pescado no atacado}

Nas atividades ocorrentes no atacado, a cadeia de intermediação, em diversos casos, inicia-se com o barco pesqueiro e com o comerciante local.

Tabela 1 - Variação de preços entre diferentes agentes de produção e comercialização de pescado em Manaus entre agosto e setembro de 1995 (US\$1 = R\$ 0,95).

\begin{tabular}{lllll}
\hline \hline \multirow{2}{*}{ Item } & tambaqui & \multicolumn{2}{c}{ pescada tucunaré pirarucu } \\
\cline { 2 - 5 } & $(\mathrm{R} \$ / \mathrm{kg})$ & $(\mathrm{R} \$ / \mathrm{kg})$ & $(\mathrm{R} \$ / \mathrm{kg})$ & $(\mathrm{R} \$ / \mathrm{kg})$ \\
\hline $\begin{array}{l}\text { Preço pago } \\
\text { ao pescador }\end{array}$ & 0,55 & 0,50 & 0,80 & - \\
$\begin{array}{l}\text { Preço pago } \\
\text { no atacado }\end{array}$ & 3,00 & 2,00 & 2,50 & 2,50 \\
$\begin{array}{l}\text { Preço no } \\
\text { varejo }\end{array}$ & 5,00 & 3,00 & 3,00 & 4,00 \\
\hline \hline
\end{tabular}

Os barcos pesqueiros, geralmente pequenos e médios, e o comerciante local compravam a produção do pescador ribeirinho dependente, que é o ribeirinho que pesca para venda atrelado a um determinado barco pesqueiro ou ao comerciante local (Parente, 1995). Este pescador reside usualmente em lugares distantes dos centros consumidores e só tem acesso ao mercado através destes dois agentes. Geralmente, comercializa espécies de alto valor comercial como tambaqui (Colossoma macropomum), pirarucu (Arapaima gigas) e tucunaré (Cichla spp.). A produção entregue ao barco ou ao comerciante era paga à vista depois de descontados, se for o caso, o fornecimento do rancho, ou o dinheiro que é deixado com a família do pescador e os gastos com os componentes para recuperação dos apetrechos de pesca. Esses agentes levavam a produção até Manaus onde era comercializada via despachante. Já o ribeirinho que pesca sem nenhum vínculo a qualquer barco ou comerciante é denominado "pescador ribeirinho autônomo" (Parente, 1995), vendendo sua produção diretamente aos feirantes, aos frigoríficos, aos barcos de recreio e aos pequenos comerciantes varejistas sem a intermediação do despachante.

O despachante é o segundo tipo de agente em ação, e o mais importante dentro dessa cadeia de intermediação, estando presente em quase todos os casos de comercialização no atacado. Ele atuava como agente encarregado de realizar a comercialização do pescado no atacado em Manaus, além de freqüentemente financiar as viagens de pesca dos barcos com que trabalha. É a partir dele que se iniciava o processo de comercialização, concentrando em suas mãos praticamente a totalidade do comércio atacadista de pescado em Manaus, tanto as pertencentes ao "pequeno pescador" como as do "armador".

A comercialização no atacado se realiza na beira do rio, no entorno de uma balsa de apoio chamada de "Terminal Pesqueiro", embora este não possua características de um verdadeiro terminal de desembarque (Batista, 1998). Esteve localizado até 1992 atrás do mercado Municipal Adolpho Lisboa, passando para o porto da feira da Panair, no bairro de Educandos até 1997 , retornando ao antigo porto até junho de 2005 e à Panair desde então. Em ambos locais, há condições favoráveis de atracação dos barcos e desembarque do pescado, embora no Adolpho Lisboa seja melhor para pescadores e armadores em termos de segurança e comercialização. Assim, todos os barcos pesqueiros que comercializam sua produção em Manaus dirigem-se para esse local a noite, onde se desenvolvia o primeiro circuito de troca, que é chamado de "leilão noturno", iniciando-se às 22:00 horas e encerrando-se às 4:00 horas.

A estrutura do "leilão noturno" se organizava então dentro de dois espaços: um principal, nos próprios barcos que ficam ancorados nas proximidades da balsa de apoio; e o outro, em terra, em caminhões localizados na pista em frente a balsa ou em um barracão localizado na Panair, onde alguns barcos ancoram e comercializam sua produção.

Para realizar a comercialização nos barcos, o despachante se posiciona no próprio barco que "despacha", à espera de compradores (feirantes, comerciantes varejistas, intermediários atacadistas e frigoríficos) que se deslocam até às embarcações 
em "catraias" (canoas locais), alugadas de terceiros, que ficam atracadas no "porto de desembarque" exclusivamente para esse fim. Quando o despachante tem, por noite, mais de um barco para comercializar o produto, as embarcações que "despacha" eram colocadas uma ao lado da outra.

O pescado era colocado no convés do barco, separado por espécie, para apreciação dos compradores. Os preços também variavam por espécie. Assim, o pescado considerado nobre e preferido pela população de maior poder aquisitivo, como o pirarucu, tucunaré, tambaqui e pescada (Plagioscion spp.) tinham os preços mais elevados. Os pescados mais populares como jaraqui (Semaprochilodus spp.), pacu (Myleinae), branquinha (Curimatidae) tinham preços mais acessíveis. Contudo, dentro da mesma espécie, na mesma noite, podia existir diferença de preço, pois o tamanho, frescor e teor de gordura eram levados em consideração. Conforme a procura, o preço podia sofrer redução até o limite em que podia cobrir pelo menos o custo das viagens, caso contrário as vendas eram suspensas, adiando-as para o dia seguinte no intuito de conseguir um melhor preço para o produto.

Quanto à realização do "leilão" em terra, que funciona na feira fixa da Panair, o esquema de funcionamento obedecia às mesmas regras que vigoravam no "leilão" dos barcos.

Para avaliação dos compradores o pescado também era separado por espécie e colocado em caixas de madeira medindo, aproximadamente, $2 \mathrm{~m}$ de comprimento por $1,5 \mathrm{~m}$ de largura. Neste "leilão" os despachantes (entre os quais incluem-se os prepostos dos despachantes que trabalham nos barcos) comercializavam preponderantemente "peixes miúdos" para atendimento a um público específico, os feirantes ambulantes, ou seja, aqueles feirantes que utilizam um pequeno caminhão ou kombi para vender o pescado em vários bairros, e os pequenos vendedores (peixeiros) que possuem bancas de peixes nos bairros. Só que aqui o preço de venda geralmente era mais elevado do que o que é praticado nos barcos, porque ocorrem gastos com carregadores para o transporte do pescado dos barcos até essas caixas. No entanto, esses gastos eram irrisórios, pois à época da pesquisa (agosto-setembro/95) o preço para o transporte de 30.000 peixes ("peixes miúdos") correspondia a $\mathrm{R} \$ 15,00$ (US\$1 $=\mathrm{R} \$ 0,95$ ) o que onerava o preço de um cento de peixes em apenas $\mathrm{R} \$ 0,05$.

Um terceiro tipo de agente atacadista eram os "intermediários" ou "atravessadores", que eram aqueles atacadistas que compram o pescado dos despachantes já no final do "leilão" e por isso a preços bem acessíveis. Por esse motivo, podem revendê-lo, muitas vezes, a preços até inferiores aos do "leilão" e atendem a feirantes que não participavam do "leilão noturno", devido ao horário de funcionamento, e a feirantes inadimplentes com os despachantes. A venda era realizada à vista ou à prazo, com 24 horas para o pagamento que era recebido pelo próprio intermediário e no local de trabalho do feirante. A participação destes intermediários no fornecimento de pescado aos feirantes era importante, pois $16 \%$ dos feirantes entrevistados responderam que compram dos intermediários parte do pescado que comercializam.
O último tipo de agente intermediário atacadista importante nesse processo eram os donos dos frigoríficos. Estes, normalmente, são comerciantes capitalistas e constituiam um grupo autônomo que não eram despachantes e nem armadores embora possam ser proprietários de barcos de pesca. Na essência podem ser considerados comerciantes e não produtores.

Existiam então três grandes frigoríficos responsáveis por parte do abastecimento de pescado em Manaus através do fornecimento a supermercados, distrito industrial, hotéis, restaurantes e venda direta a varejo. No entanto, o principal mercado destes frigoríficos eram os mercados nacional e internacional que, em conjunto, representavam $79 \%$ de todo o pescado por eles comercializado. Além desses frigoríficos, existiam outros menores que continham pequenas câmaras de resfriamento de pescado, voltados para o atendimento do mercado interno principalmente hotéis, restaurantes, distrito industrial e feirantes.

A pesquisa considerou quatro frigoríficos que totalizavam uma capacidade de estocagem de $2.812 \mathrm{t}$ com uma taxa de ocupação de quase $100 \%$ na época da safra e de $19 \%$ na entressafra. No ano de 1995 foram adquiridas por esses frigoríficos $7.191 \mathrm{t}$ e comercializadas 4.139,2 $\mathrm{t}$ atendendo o mercado local, nacional e exterior. Do total comercializado, $74 \%$ foram vendidas para o mercado nacional, $14 \%$ para o distrito industrial, 5\% para o mercado exterior, $4 \%$ para os supermercados e o restante (cerca de 3\%) para hotéis, restaurantes, feirantes e venda direta no varejo.

Os frigoríficos comercializaram o pescado no atacado com pequeno beneficiamento que consiste na descamação e evisceração, sendo vendidos inteiros, em postas e em filés. Os peixes de escamas que possuem muitas espinhas, além de descamados e eviscerados são "ticados", que consiste de pequenos golpes transversais ao lombo bem próximos uns dos outros com o objetivo de cortar as espinhas facilitando a ingestão.

\section{Venda do pescado no varejo}

Quanto aos comerciantes varejistas, os feirantes representam a parcela mais numerosa. Segundo os dados de recadastramento realizado pela Prefeitura no ano de 1995, existiam 505 boxes de peixes nas feiras e mercados de Manaus. Com base nesse recadastramento e nos dados da pesquisa realizada em cinco feiras e mercados considerados representativos (Feira da Panair, Feira Manaus Moderna, Mercado Adolpho Lisboa, Mercado da Cachoeirinha e Mercado Armando Mendes), foi efetuada uma estimativa destes intermediários em 1995, para avaliar a sua importância no mercado. Considerando a quantidade comercializada na safra e na entressafra, por semana, nas feiras e mercados pesquisados, foi efetuada uma extrapolação para o total de feirantes, chegando a um valor correspondente a, aproximadamente, $8.800 \mathrm{t}$ de pescado comercializado em 1995. Deste total, a Feira da Panair comercializou cerca de 2.720 to que equivale a $31 \%$ 


\section{ACTA AMAZONICA}

de todo o pescado comercializado nas feiras e mercados. Segundo a estimativa feita pelos próprios feirantes da Panair, esta feira era responsável por $20 \%$ do abastecimento total de pescado in natura no varejo em Manaus. Isto sendo real, o total de pescado in natura comercializado naquele ano pelos feirantes, inclusive os ambulantes e peixeiros atingiu cerca de 13.600 t, o que representou cerca de $50 \%$ de toda a produção controlada que desembarcou em Manaus em 1995.

A heterogeneidade dos feirantes aparece em diferentes níveis. Na maioria são descapitalizados e compravam pescado à prazo do despachante que lhes dava 48 horas (no máximo 72 horas) para o pagamento da dívida. É importante ressaltar que $70 \%$ dos feirantes eram financiados pelos despachantes, segundo informações dos próprios feirantes. Quando o pagamento não era realizado dentro do prazo, este era chamado, através de alto-falante antes do início do leilão, para resgatar sua dívida. Se a convocação não for atendida, seu nome fará parte da relação dos inadimplentes. Este fato significa a exclusão do feirante do "leilão noturno".

Mas ao lado destes feirantes, existiam feirantes importantes que movimentavam um volume de recursos relativamente altos para os padrões destes intermediários, visto que além de atenderem ao público em geral, atendiam também restaurantes, hotéis, distrito industrial, e afins, chegando mesmo a comercializar para o mercado nacional. De fato, dos 51 feirantes entrevistados na pesquisa de campo, 2 exportavam para outros estados como Rondônia, Pará, Distrito Federal e São Paulo e 16 forneciam pescado para 35 restaurantes em Manaus com os quais, via de regra, mantinham contratos formalizando a venda, o que significa a garantia de mercado de uma parte do pescado que comercializam. Existiam também feirantes que desempenhavam outras atividades na pesca como as de armador e de despachante, o que acentua a diferenciação entre eles. Esta condição permite a estes feirantes que até contratem auxiliares ou prepostos que eram remunerados semanalmente, sendo que para os primeiros o pagamento variava entre $\mathbf{R} \$$ 50,00 e R \$ 70,00 (US\$ 52,6-73,7), e para os últimos corresponde a $50 \%$ do lucro gerado com a venda, os outros $50 \%$ pertencem ao proprietário do boxe.

Outros tipos de intermediários varejistas eram os supermercados e os pequenos comerciantes varejistas. De acordo com os frigoríficos que pesquisamos, que eram os principais fornecedores destes agentes (supermercados), $4 \%$ do que comercializavam era destinadoàs duas mais importantes redes de supermercados existentes em Manaus, que juntas comercializaram em 1995 pelo menos $168 \mathrm{t}$ de pescado, o que representava menos de $1 \%$ do total desembarcado naquele ano em Manaus. Entretanto seus preços, por conta do beneficiamento, eram muito altos. Por exemplo, em agosto de 1995, os preços por quilo de produtos pesqueiros nos supermercados (pirarucu e pescada fresco; filé de surubim, pescada e tucunaré; posta de surubim, dourada e tambaqui) se situaram entre R\$4,9 e R\$8,90 (US\$ 5.2 - 9.4), conforme o produto.
Quanto aos pequenos comerciantes varejistas, as informações ainda foram mais difíceis devido a dispersão destes comerciantes, mas, certamente, a participação deles no mercado também era minoritária. Foram encontrados dois tipos deste agente: aqueles que têm o peixe como o único produto que comercializam, ou seja, são especialistas na venda do pescado e aqueles que não são especialistas, os taberneiros, ou seja, dentre os produtos que comercializam inclui-se também o pescado. Os primeiros se localizam nas áreas mais centrais ou bairros mais nobres e dispõem de melhores condições de trabalho no que e refere à infra-estrutura para comercialização do produto - como balcóes frigoríficos e freezer para acondicionamento do pescado e carros utilitários para o transporte - contratando trabalhadores para realizar o beneficiamento e atividades afins. Comercializavam o pescado nas mesmas condições dos supermercados, isto é, congelados e beneficiados e por isso os preços são equivalentes. Já os taberneiros, que estavam localizados em vários bairros da cidade, suas condições de trabalho eram mais precárias, acondicionavam o pescado em freezer, e a comercialização do produto era realizada sem nenhum beneficiamento. Mas mesmo nessas condições tinham boa aceitação nos locais onde atuavam porque eram peixes frescos adquiridos junto aos "pescadores ribeirinhos". Os preços variaram de bairro para bairro, dependendo do poder de compra dos moradores mas foram mais elevados do que os cobrados nas feiras e mercados.

A estrutura de comercialização do pescado em Manaus vigente no período pode ser melhor visualizada no esquema da figura 1 , onde podemos perceber a importância do despachante dentro deste processo porque é a partir dele que tinha início a comercialização do pescado em Manaus.

De fato, logo que o barco aporta em Manaus, a produção ficava à disposição do despachante para ser comercializada. $\mathrm{O}$ despachante, então, como é um agente que permanece em Manaus já providenciava a "colocação" da mercadoria para os diferentes consumidores constituídos por feirantes, feirantes

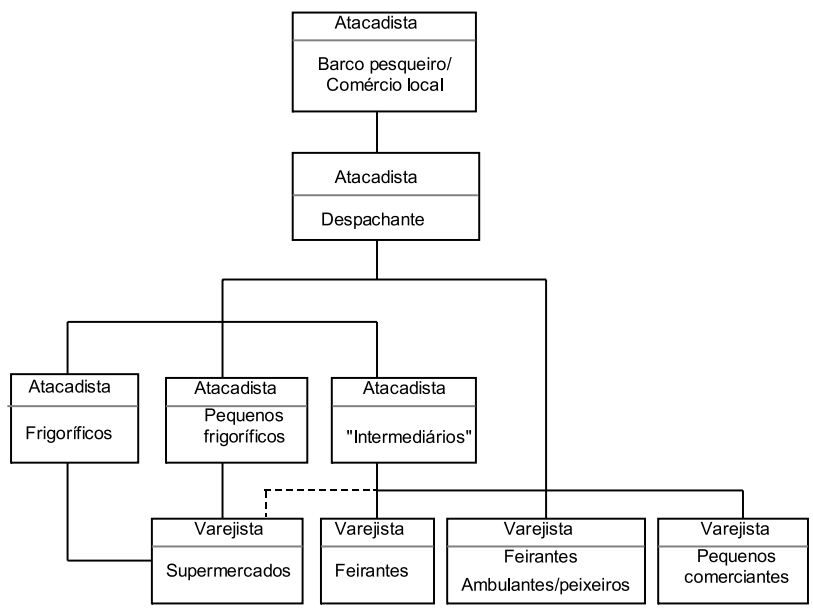

Figura 1 - Estrutura de organização da comercialização do pescado em Manaus. A linha pontilhada indica relacionamento secundário. 
ambulantes, peixeiros, comerciantes varejistas, restaurantes, frigoríficos e mercado nacional. Ele era assim, o centro para onde convergiam as forças do mercado. Essa realidade pode ser expressa através do seguinte esquema (Fig. 2).

Era também o despachante quem financiava tanto a comercialização quanto a produção. No âmbito da comercialização, comprava a produção efetivamente comercializada através do "leilão", pagando ao pescador à vista, agilizando assim, sua volta de imediato à pescaria. Embora o pagamento ao pescador seja à vista, no geral, a venda era feita à prazo, principalmente para os feirantes que, na maioria, são descapitalizados e para os quais é dado um prazo de, no máximo, 72 horas para o resgate da dívida junto ao despachante. Isto demonstra que, no fundo era o despachante quem comprava e vendia o produto no atacado. E é por isso que os compradores tinham uma dívida a pagar, não ao "armador" ou "pequeno pescador", mas ao despachante, o que significa que este agente financiava também os feirantes, por exemplo, que constituem a maior parcela da demanda. Portanto, tinham controle total da comercialização, estando em suas mãos tanto os produtores quanto parte considerável dos demandantes. Dessa forma, tinham o domínio sobre os pescadores, tanto por financiar quanto por comprar a produção e sobre os feirantes por financiar a comercialização. O esquema a seguir expressa o domínio do despachante (Fig. 3).

\section{DISCUSSÃO}

A comercialização é elemento importante para a viabilização da atividade produtiva agrícola. É uma etapa que necessita ser realizada de imediato, devido a especificidade inerente à uma atividade geradora de produtos altamente perecíveis e com grade oscilação dos preços, falta de controle da oferta em resposta a uma variação no comportamento da demanda, falta de infra-estrutura de armazenamento, dificuldades de

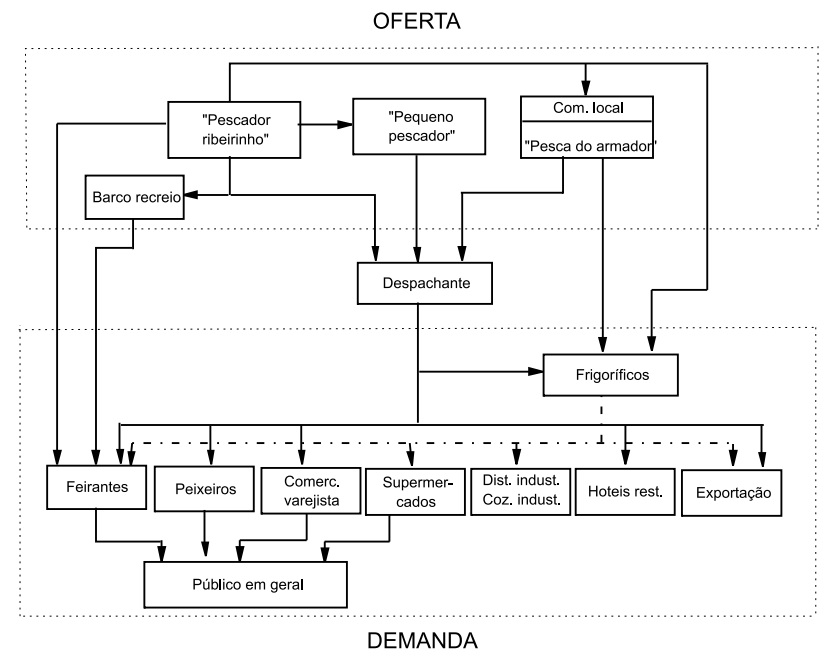

Figura 2 - Estrutura da oferta e demanda de pescado em Manaus. A linha tracejada indica relacionamento secundário. escoamento da produção, dentre outros (Santana, 1998). Por isso, os produtos agrícolas, geralmente, têm uma extensa cadeia de intermediação entre o produtor e o consumidor final, sendo a responsável pelo encarecimento dos preços finais de mercado.

No caso da pesca em Manaus, essa situação pode ser constatada através da complexa cadeia de intermediação, onde é destacada a figura do despachante como agente central dentro do processo de comercialização. A maior parte da produção de pescado em maior escala foi comercializada durante a década de 90 por esse agente. Este papel chave do intermediário é frequentemente observado no escoamento da produção rural, incluindo a pesqueira, na Amazônia (Furtado, 1993; Santana, 1998).

De fato, mesmo a produção do pescador ribeirinho dependente é vendida indiretamente através do despachante. É que estes pescadores vendem sua produção para os pequenos barcos pesqueiros que pescam nas comunidades rurais e para os comerciantes rurais. Estes dois intermediários comercializam essa produção adquirida dos pescadores ribeirinhos dependentes em Manaus, através do despachante.

Isto se dá por causa da distância dos locais de pesca para o centro de comercialização (Petrere, 1978; Batista, 1998) que determina dificuldades e custos de transporte e problemas sérios de acesso ao mercado, monopolizado pelos agentes de intermediação. Em vários casos, a magnitude destas dificuldades são tão grandes que dois ou três intermediários são necessários antes do produto chegar ao consumidor final, aumentando o custo final ao consumidor ou demandando subsídios para manter a frota ativa (Schrank, 2003; Westlund, 2004). A exceção é feita ao pescador ribeirinho autônomo, o qual comercializa sua produção diretamente e com rapidez, visto que reside nas proximidades dos centros consumidores e considerando sua pequena produção. Neste caso, deve-se atentar para o incremento do individualismo competitivo dos responsáveis

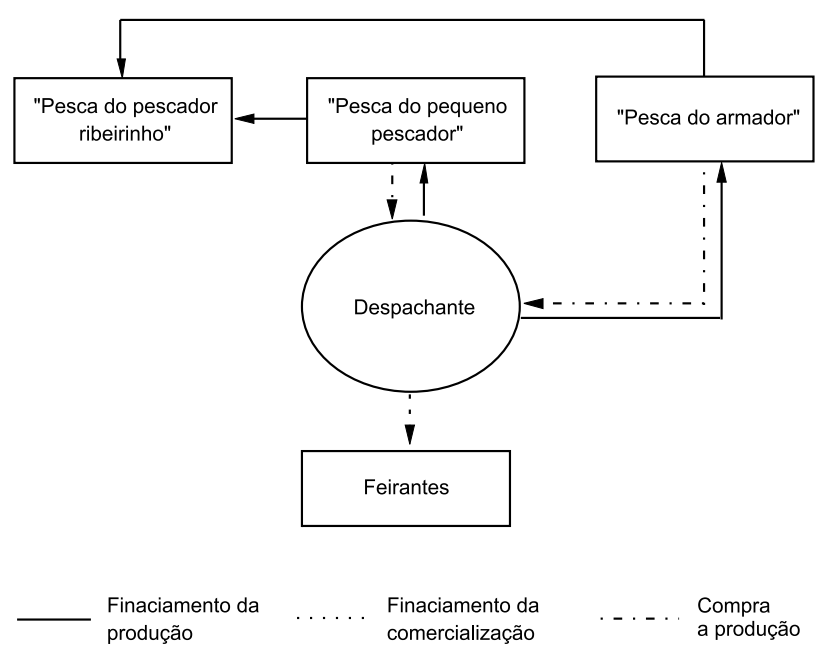

Figura 3 - Diagrama demonstrativo do processo de dominação do despachante através do controle do fluxo do pescado. 


\section{ACTA AMAZONICA}

pela comercialização dos produtos pesqueiros, o que pode exigir novos arranjos sociais locais (McGoodwin, 2002).

Entregar a produção pesqueira ao despachante significava comercializar a produção à noite, durante o "leilão noturno" que funcionava no horário de 22:00 às 4:00 horas, um horário inconveniente para a realização de viagens em embarcações utilizadas pelo pescador ribeirinho autônomo. Os pescadores ribeirinhos autônomos usualmente já têm compromissos estabelecidos com feirantes e pequenos comerciantes varejistas para o fornecimento semanal de peixes, normalmente recebendo o pagamento à vista. Para otimizar sua ação, estes pescadores utilizam o "barco de recreio" para transportar o produto até Manaus, melhorando seu lucro. Isto gera estimulo para que outros "pescadores ribeirinhos" vendam sua produção em Manaus, fato que afeta o movimento diário de compra de pescado através do leilão no porto de desembarque. Tais ações e reações mostram a simplicidade deste mercado em que produtos não processados predominam na comercialização, o que permite a manutenção de sistemas de comercialização tradicionais direto do produtor ao consumidor (MacKenzie, 1983).

Para o "pequeno pescador" e para o "armador", o comerciante "despachante" apresenta uma função importante na comercialização no atacado. Isto ocorre, porque a escala de produção dessas embarcações já necessita ser comercializada com rapidez em decorrência da alta perecibilidade e da pressa de converter o produto em dinheiro. E é exatamente o despachante que realiza esse processo no sentido de que compra, no atacado e à vista, toda a produção que foi "colocada" previamente no mercado através do "leilão". Age assim como um agente de crédito que viabiliza o escoamento da produção pesqueira que chega a Manaus, ocupando um espaço vazio pela falta de políticas públicas adequadas para o setor. Além disto, é freqüente que sirva como um agente securitário em pescarias artesanais de pequena escala (McGoodwin, 2002) como a que abastece Manaus, devido a incapacidade dos setores governamentais e privados de lidar com a escala e dinâmica do setor, o que causa aumentos nos custos para o segmento.

Por esse duplo perfil de comerciante e financiador das viagens de pesca, o despachante afeta o preço do pescado, embora a variação dos preços seja explicada por outros fatores, dentre os quais o aumento da oferta. Isto acontece particularmente nos períodos de safra, quando há uma maior quantidade de barcos comercializando pescado, acirrando a concorrência entre os vendedores. Dessa forma, os barcos necessitam de maior tempo para comercializar sua produção que chega até a sete dias de acordo com sua capacidade de estocagem. Este fato é responsável por um desperdício de pescado estimado entre 2\% (com. pess., Pedro Paulo Parente - Associação de Despachantes do Estado do Amazonas, atual Associação de Armadores) e 13\% (com. pess., Wilson Ribeiro Federação de Pescadores do Amazonas) por barco e que é jogado no rio. Ressalte-se que os barcos que capturam peixes de maior valor comercial vendem mais rapidamente suas mercadorias porque são espécies preferidas por restaurantes, hotéis, frigoríficos, distrito industrial e supermercados. Nesses casos, a oferta parece ser menor do que a demanda, mesmo na época de safra, o que agiliza a venda.

O "leilão" que ocorre em terra na Panair perdeu importância com o deslocamento da balsa de Desembarque do Pescado para o Adolpho Lisboa, porém segue como local onde é comercializado pescado para compradores que optam por adquirir um pescado mais caro, mas evitando os gastos com catraias, carregadores, e outros, o que efetivamente é compensador dependendo da qualidade e da quantidade do pescado adquirido. Sua importância histórica está em mostrar que existe um potencial de venda por atacado em terra, com compradores dispostos a adquirir pescado para venda neste sistema.

Os "comerciantes atravessadores" usualmente não têm contato direto com os pescadores e têm trazido algumas inconveniências aos despachantes, principalmente por gerar uma irregularidade na demanda, porque compram pescado mais barato e em quantidade suficiente para abastecer os feirantes por até uma semana. Isto lhes permite revender o pescado frequentemente a preços inferiores aos do leilão e com maiores facilidades operacionais para os feirantes. Com isto vários feirantes deixam de participar do leilão, e os feirantes inadimplentes com os despachantes continuam em atividade. Porém, sua presença é benéfica por permitir o aumento da teia de comercialização da produção, permitindo que o pescado esteja mais acessível para o consumidor de menor renda. Este caminho é interessante desde que condições de comercialização simples mas adequadas sejam implementadas, o que é possível com tecnologia conhecida (Medina-Pizzali, 1997), mas que demanda atenção de políticas públicas voltadas a segurança alimentar na região.

A estratégia do "comerciante frigorífico" é de adquirir o pescado na safra a preços baixos e vendê-lo na entressafra quando os preços tendem a aumentar. Fica evidente, assim, que este talvez seja o único agente na estrutura de comercialização em Manaus que tem condições de utilizar a capacidade de estocagem que dispóe como elemento de especulação na comercialização e que lhe permite, portanto, adquirir a preços mais baixos e vender a um preço mais alto. $\mathrm{O}$ lucro especulativo, nesse sentido, nada mais é do que o prêmio pelo risco inerente ao "transporte no tempo" de uma mercadoria (Hilferding apud Maluf, 1992).

Os "comerciantes frigoríficos" também são particulares por agregarem valor ao produto para a comercialização do pescado no atacado, o que se deve a uma exigência do público especifico e em expansão que atendem, que são os supermercados, hotéis, restaurantes, distrito industrial e o mercado nacional e exterior.

Concluiu-se neste trabalho que o despachante atuou na década de 90 como um agente central no processo de comercialização. O despachante apresentou domínio não só sobre os pescadores, porque financia a produção, mas também sobre a principal parcela dos comerciantes varejistas, os feirantes, através dos financiamentos simplificados. Representaram, portanto, os agentes que aplicam maior volume de recursos financeiros na atividade, sendo os principais 


\section{ACTA AMAZONICA}

A ORGANIZAÇÃO DO DESEMBARQUE E O COMÉRCIO DE PESCADO NA DÉCADA DE 1990 EM MANAUS, AMAZONAS. representantes do capital comercial que se apresentou ainda hegemônico na pesca em Manaus durante o período de estudo.

Sabe-se que uma extensa cadeia de intermediação sempre traz reflexos nos preços, representando uma redução ao produtor e uma elevação ao consumidor, sendo a diferença entre esses dois extremos tanto maior quanto mais extensa for a cadeia de intermediação (Seijo et al., 1997). No caso da pesca que abastece Manaus, mesmo que a cadeia de intermediação não apresente muitos níveis, os preços do pescado são elevados para o consumidor, demonstrando que restringir a cadeia de intermediação não garante, necessariamente, uma maior eficiência da comercialização no sentido de beneficiar tanto os pescadores quanto os consumidores, porque este não é o objetivo dos comerciantes. Tampouco não se deve responsabilizar apenas os intermediários pelo elevado nível do preço do pescado, embora a ineficiência do processo contribua diretamente para isto. $\mathrm{O}$ poder público é também co-responsável e deve efetuar a gestão da distribuição do comércio do pescado na cidade de forma a garantir a qualidade sanitária do produto e sua disponibilização de acordo com o público-alvo existente e previsto dentro da escala de crescimento local.

\section{AGRADECIMENTOS}

Agradecemos à Capitânia dos Portos, Colônia de Pescadores, Associação de Despachantes e Associação de Armadores pelo acesso a informações utilizadas neste trabalho e aos técnicos e professores que colaboraram no desenvolvimento das atividades, particularmente o Prof. Dr. Nelson Delgado da UFRRJ.

\section{BIBLIOGRAFIA CITADA}

Batista, V.S. 1998. Distribuição, dinâmica da pesca e dos recursos pesqueiros na Amazônia Central. Tese de doutorado, INPA/FUA. Manaus. 291 pp.

Furtado, L.G. 1993. "Reservas pesqueiras", uma alternativa de subsistência e de preservação ambiental: Reflexões a partir de uma proposta de pescadores do médio Amazonas. In: Furtado, L.; Mello, A.F.; Leitão, W. Povos das Águas realidade e perspectiva na Amazônia. Belém, MPEG/UFPA. p243-276.

Junk, W.J.; Honda, E.M.S. 1976. A pesca na Amazônia. Aspectos ecológicos e econômicos. In: Anais do I Encontro Nacional sobre limnologia, piscicultura e pesca continental. Belo Horizonte, Fundação João Pinheiro. p211-226.

Loureiro, V.R. 1985. Os parceiros do mar: natureza e conflito social na pesca da Amazônia. CNPq/Museu Paraense Emílio Goeldi. Belém. 227pp.

MacKenzie, W.C. 1983. An introduction to the economics of fisheries management. FAO Fisheries Technical Paper, 226, FAO, Roma. 31 pp.
Maluf, R.S. 1992. Comercialização agrícola e Desenvolvimento Capitalista no Brasil. Revista de Economia Politica, 12(3), 46-57.

Martins, J.S. 1998. O cativeiro da terra. 7. ed. Hucitec: São Paulo 157 pp.

McGoodwin, J.R. 2002. Comprender las culturas de las comunidades pesqueras: clave para la ordenación pesquera y la seguridad alimentaria. FAO Documento Técnico de Pesca, 401, FAO, Roma. 301 pp.

Medina-Pizzali, A.F. 1997. Equipos e instalaciones de bajo costo para la comercialización minorista de pescado. FAO Documento Técnico de Pesca, 363, FAO, Roma. 105 pp.

Mello, A.F. 1993. Pescadores da indústria: o complexo de Icoaracy. In: Furtado, L.; Mello, A.F.; Leitão, W. Povos das Águas realidade e perspectiva na Amazônia. MPEG/UFPA. Belém. p.83-100.

Mendes, J.T.G. 1989. Economia agrícola: princípios básicos $e$ aplicações. Scientiae et Labor. Curitiba. 399 pp.

Parente, V.M. 1996. A economia da pesca em Manaus: Organização da produção e da comercialização. Rio de Janeiro, Dissertação de mestrado, UFRRJ. 178 pp.

Petrere, M. 1978. Pesca e esforço de pesca no estado do Amazonas. II. Locais e aparelhos de captura e estatística de desembarque. Acta Amazonica 8(Suplemento 2), 1- 54.

Santana, A.C. 1998. Cadeias agroindustriais e crescimento econômico na Amazônia: análise de equilíbrio geral. In: Homma, A.K.O. (Ed) Amazônia: meio ambiente $e$ desenvolvimento agrícola. EMBRAPA, Belém, Brasil. p. 221264.

Schrank, W.E. 2003. Introducing fisheries subsidies. FAO Fisheries Technical Paper, 437, FAO, Roma. 52 pp.

Seijo, J.C.; Defeo, O.; Salas, S. 1997. Bioeconomía pesquera. Teoría, modelación y manejo. FAO Documento Técnico de Pesca, 368. FAO, Roma. 176 pp.

Westlund, L. 2004.Guía para la identificación, evaluación y presentación de informes de las subvenciones en el sector pesquero. FAO Documento Técnico de Pesca, 438, FAO, Roma. 81 pp.

Zamosc, L. 1979. Notas Teóricas sobre la Subordinación de la Producción Mercantil Campesina al Capital. Estudios Rurales Latinoamericanos. 2(3):296-305.

RECEBIDO EM 21/02/2003 ACEITO EM 15/09/2005 